\title{
Impact on interpersonal relationships among patients with multiple sclerosis and their partners
}

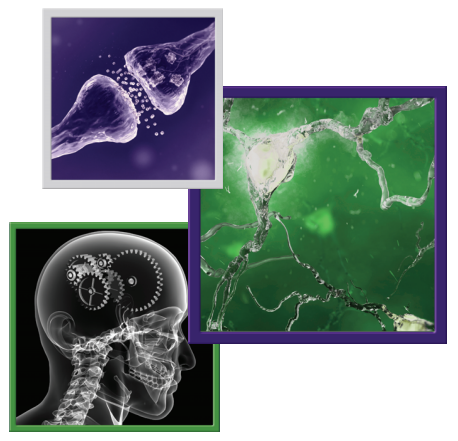

\author{
Leslie Beth Herbert ${ }^{1}$, Kristine Zerkowski², Sarah O’Brien ${ }^{3}$, Kathryn Volpicelli Leonard*,2 \& \\ Amrita Bhowmick ${ }^{2,4}$ \\ ${ }^{1}$ Research \& Analytics, Health Union LLC, 1 International Plaza Dr \#550, Philadelphia, PA, USA \\ ${ }^{2}$ Community Development, Health Union LLC, 1 International Plaza Dr \#550, Philadelphia, PA, USA \\ ${ }^{3}$ Contractor, Health Union LLC, Chapel Hill, NC, USA \\ ${ }^{4}$ Department of Health Behavior, Gillings School of Global Public Health, University of North Carolina School of Medicine, Chapel \\ Hill, NC, USA \\ *Author for correspondence: kate.leonard@health-union.com
}

\section{Practice points}

- Participants were equally likely to report feeling that their health problems burdened their partner and were glad that their partner is understanding.

- Multiple sclerosis (MS) participants generally have few negative perceptions of relationships with romantic partners, children and close friends.

- MS participants did describe the impact of fatigue and limited mobility as feelings of being not well-understood by others, burdensome and isolated.

- More than half of individuals at all levels of disability and pain severity report being satisfied with their relationship with romantic partners, except for a small dip among patients with moderate disability.

- Compared with patients with fibromyalgia, patients with MS were more likely to report relationship satisfaction and a more positive level of understanding from their partner.

- Relationship counseling might help couples to develop realistic expectations and healthy coping strategies.

- Parental illness can be a major source of stress and uncertainty for children, and unfortunately, research in this area is limited.

Aim: To determine how the diagnosis and symptoms of multiple sclerosis (MS) impact interpersonal relationships. Participants \& methods: Data were obtained from a convenience sample of 1010 individuals with MS responding to an online survey; responses were compared with results of a fibromyalgia survey. Results: MS participants had few negative perceptions of relationships with romantic partners/children/close friends but described the impact of fatigue and limited mobility as feelings of being not well understood by others, burdensome and isolated. Conclusion: Despite increasing disability/pain severity, most patients with MS reported high satisfaction levels and few negative perceptions of relationships with romantic partners/children/close friends. Future research should focus on identifying effective coping strategies used by satisfied couples and improving access to high-quality relationship-enrichment programs.

First draft submitted: 30 October 2018; Accepted for publication: 3 April 2019; Published online: 22 May 2019

Keywords: autoimmune $\bullet$ chronic health $\bullet$ disability $\bullet$ fibromyalgia $\bullet$ multiple sclerosis $\bullet$ pain severity $\bullet$ quality of life $\bullet$ relationships

Multiple sclerosis (MS) is a chronic, debilitating autoimmune disease of the central nervous system (CNS) [1]. MS is characterized by the destruction of myelin and oligodendrocytes, leading to the formation of lesions and axonal loss in CNS [1]. Symptoms vary greatly from person to person but can include fatigue, paresthesia, gait disturbances, loss of balance, vision loss, bowel and bladder dysfunction, and sexual dysfunction [2,3]. Over time, as MS progresses, many people with the disease must increasingly rely on their partners to help them manage symptoms and perform activities of daily living [4]. 
The onset of MS usually occurs in early adulthood at a time when many long-term relationships are established between individuals [5]. Previous studies have shown that the burden of the physical and psychological effects of MS can have a profound impact on couples and their relationships over time [5,6].

This study examines the impact of a diagnosis of MS and how MS symptoms such as fatigue, pain and mobility limitations can affect interpersonal relationships with spouses or partners, children and close friends. These data were also evaluated in comparison with results of a separate study of relationships in people with fibromyalgia, a chronic disabling condition that is characterized by similar symptoms, including fatigue, pain and mobility difficulties [7].

\section{Participants \& methods}

Data were collected through an online survey hosted by MultipleSclerosis.net that was available from 9 September 2013 to 13 December 2013. Prior to initiation of the survey, the study was reviewed and approved by a local Institutional Review Board. Participants were informed about the voluntary nature of the survey, information being collected, anonymous nature of data collection and the expected time for survey completion. No personal identifiers were collected or stored with the data.

\section{Recruitment}

Potential participants were recruited as a convenience sample. Links to the survey were posted on MultipleSclerosis.net and the MultipleSclerosis.net Facebook page.

MS affects more than 913,000 individuals in the USA and more than 2.3 million individuals worldwide [8,9]. Participants were eligible for the survey if they were at least 18 years old and had previously received a diagnosis of MS from a neurologist. Electronic data collection was conducted through SurveyMonkey ${ }^{\circledR}$, with data protection provided through its security measures. After reviewing information about the nature of the survey, participants were provided with the survey, which consisted of up to 54 multiple choice questions and an optional free-response item. Responses were completely anonymous, with no identifiers collected; however, participants' IP addresses were used to ensure that the questionnaire could only be completed once by any individual. Duplicate entries were avoided by preventing users with the same IP address from accessing the survey more than once during the study period.

\section{Data collection}

The survey included demographic questions and questions about the effects of MS on relationships with spouses or partners, other family members and close friends. The survey also included standardized assessment measures for MS disease status, walking ability, fatigue impact, pain effect, pain levels, anxiety and relationship satisfaction, along with ratings to assess the impact of MS on lifestyle and relationships. The survey did not include a question asking type of MS. The final question was an optional, free-response item in which participants were invited to share additional observations or concerns about how MS may affect their relationships.

Multiple sclerosis disease status was measured using the Patient-determined disease steps (PDDS) scale, an ordinal rating scale for self-reporting functional disability in MS [10,11]. Patients with MS were to select from nine items; the classification that best represented their level of disability, which was then scored into a level of disability. The 12-item Multiple Sclerosis Walking Scale (MSWS-12) is a validated self-reporting measure used to assess the impact of MS on walking [12]. Patients with MS rated each item on a scale from no limitation (1) to extreme limitation (5), and ratings were converted to scores that were then summed. The higher the score on the MSWS-12, the greater the perceived impact of MS on a patient's walking ability.

The five-item version of the Modified Fatigue Impact Scale (MFIS-5) was employed to evaluate fatigue impact. In the MFIS-5, patients with MS self-rated, on a scale of never (0) to almost always (4), how often their fatigue may have affected them in the past 4 weeks [13]. The ratings were then converted to the numeric score and summed. Higher scores indicate greater levels of fatigue impact, with possible range of scores from 0 to 20 .

Two measures were employed to assess pain, a variation of the Numeric Pain Rating Scale (NRS) and the Medical Outcomes Study (MOS) Pain Effects Scale (PES). The 11-point NRS employed in the study measured typical pain severity levels, ranging from 0 (no pain) to 10 (extremely severe pain). The PES is a six-item scale for assessing pain impact level, the extent that pain and unpleasant sensations have restricted the lives of patients with MS [13]. Patients with MS self-rated how much certain symptoms interfered with six different aspects of their lives in the 
past 4 weeks using a scale of not at all (1) to an extreme degree (5). The ratings were then converted to the numeric score and summed. Higher scores indicate greater impact of pain on the mood and behavior of a patient with MS, with a possible range of scores from 6 to 30 .

For gauging relationship satisfaction, the Relationship Assessment Scale (RAS), a seven-item validated measure of relationship satisfaction, was employed [14,15]. Each item is rated on a scale from low (1) to high (5) satisfaction. Items 4 and 7 are reverse scored; values for each item are summed and an average value is calculated. Lower scores represent less satisfaction with the relationship. The RAS is a useful screening tool to identify relationship problems that may occur for couples who are married or not married [16]. Relationship satisfaction was identified as satisfied for participants scoring RAS $\geq 4$ and not satisfied for those with RAS $<4$. This cut-off has been previously used to identify relationship satisfaction [17]. The authors are not aware of previously reported studies applying the RAS to couples with a partner with MS.

To measure depression and anxiety, the Patient Health Questionnaire (PHQ-4), a four-item, standardized, ultrabrief mood disorder questionnaire was used. The PHQ-4 yields a total score (possible range: $0-12$ ), a PHQ-2 score for depression (possible range: 0-6) and a Generalized Anxiety Disorder-2 score for anxiety (possible range: 0-6).

\section{Data analysis}

Participant demographics and question responses were evaluated using descriptive statistics. Responses to the PDDS, MFIS-5 and PES scales were converted to their numeric scale for applicable analysis. The numeric ratings on the NRS were classified into four pain severity categories: no pain (0), mild pain (1-3), moderate pain (4-6) and severe pain (7-10). Relationship satisfaction was identified as satisfied for participants scoring RAS $\geq 4$ and not satisfied for those with RAS scores of $<4$. This threshold has not been applied in previous studies of MS but was used here because a score of 3 would represent average satisfaction and scores of 4 or 5 would represent better than average or good satisfaction. Using a cut-off value of 4 also appeared to be consistent with the previously mentioned report in which couples in general scored $>4$, on average, whereas couples in therapy scored $<4$, on average [14]. In our study, differences were examined between RAS satisfaction scores and participant demographics and MS symptoms.

\section{Results}

The survey was started by 1123 individuals and completed by 1010 adults who had been diagnosed with MS. A total of 109 participants were excluded from the final sample for the following reasons: three were younger than 18 years of age, 20 had not been diagnosed with MS and 90 did not complete the survey. Most participants were married females between 35 and 64 years of age (Table 1). Potential depression and anxiety were each identified in about a third of participants.

The sample included participants from all levels of disability as measured by the PDDS and all four pain severity categories; most participants were experiencing moderate to severe pain (Table 2). Participants' walking ability (MSWS-12) had an average score of 36.7; those participants who were classified on the PDDS as using a wheelchair/scooter or who were bedridden were excluded from completing the MSWS-12. The average fatigue impact (MFIS-5) score was 12.9 and the average pain effect score (PES) was 17.6.

\section{Impact of MS on current or previous relationships}

Participants were most likely to select the option that having MS had no significant impact on their relationship(s) or the option that their relationship(s) became closer (Figure 1).

A total of 90 respondents (8.9\%) reported that MS contributed to their relationship's ending; $28.0 \%$ shared their MS diagnosis when first meeting the individual and 22.0\% shared when the relationship started, whereas $34.1 \%$ waited until they were into the relationship before sharing. A majority $(61.1 \% ; n=55)$ believe that their partner ended the relationship out of fear that having a partner with MS would become a burden.

\section{Current spouse or partner relationships}

A total of 795 participants were in a relationship, and all had told their partner that they have MS. A majority of participants (66.3\%) indicated that their MS began after their relationship started. However, of those individuals who had MS prior to their relationship, a majority $(58.8 \% ; n=255)$ told the individual of their MS when they first started dating. 


\section{Table 1. Participant demographics $(n=1010)$}

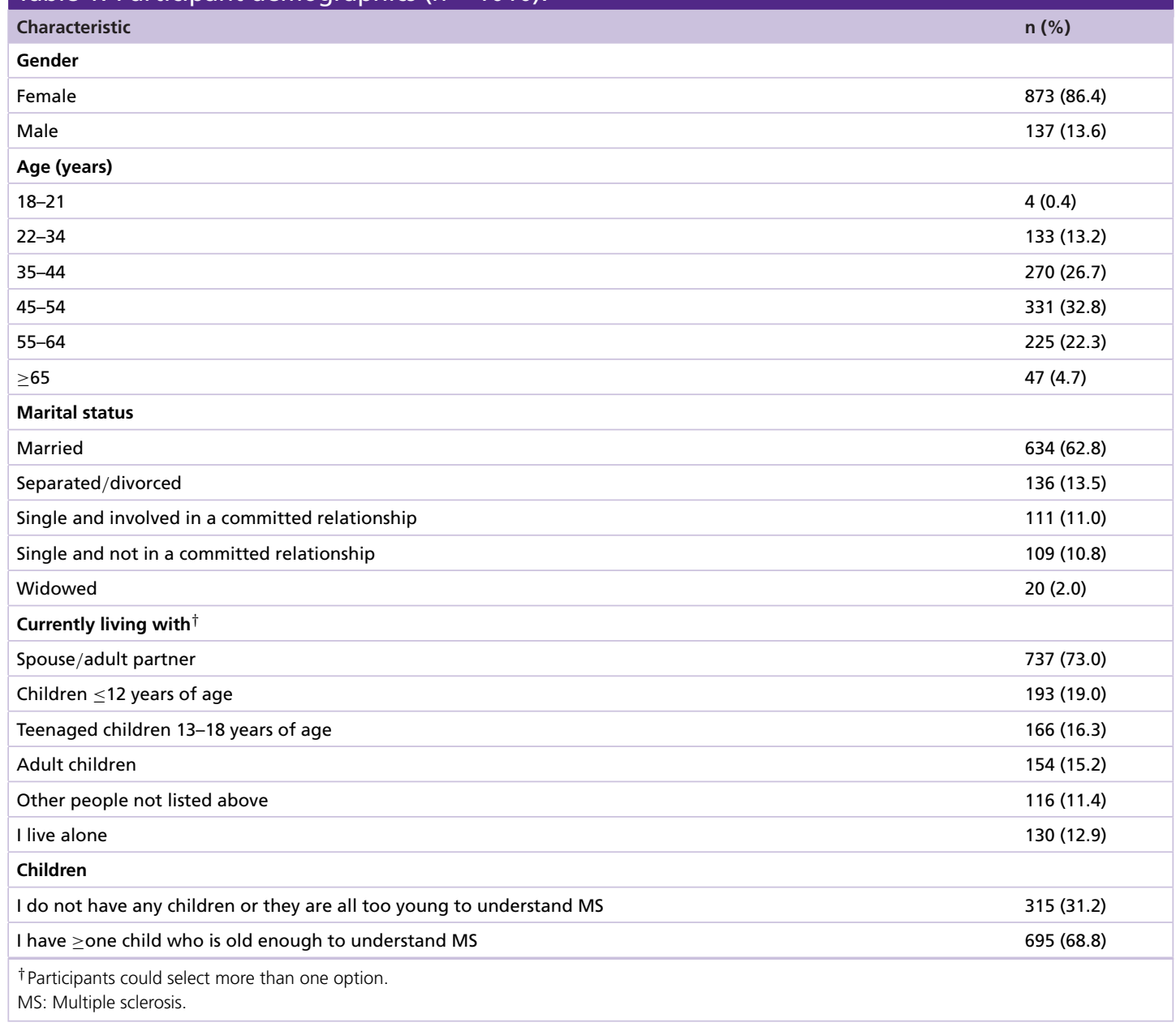

\begin{tabular}{|c|c|}
\hline Being treated with an MS disease-modifying medication & $752(74.5)$ \\
\hline \multicolumn{2}{|l|}{ Level of disability (PDDS): } \\
\hline - Normal & $148(14.7)$ \\
\hline — Gait disability & $182(18.0)$ \\
\hline - Early cane & $186(18.4)$ \\
\hline - Late cane & 140 (13.9) \\
\hline — Bilateral support & $55(5.4)$ \\
\hline \multicolumn{2}{|l|}{ Pain severity category: } \\
\hline — No pain & $110(10.9)$ \\
\hline — Mild pain & $283(28.0)$ \\
\hline - Moderate pain & $317(31.4)$ \\
\hline - Severe pain & $300(29.7)$ \\
\hline
\end{tabular}




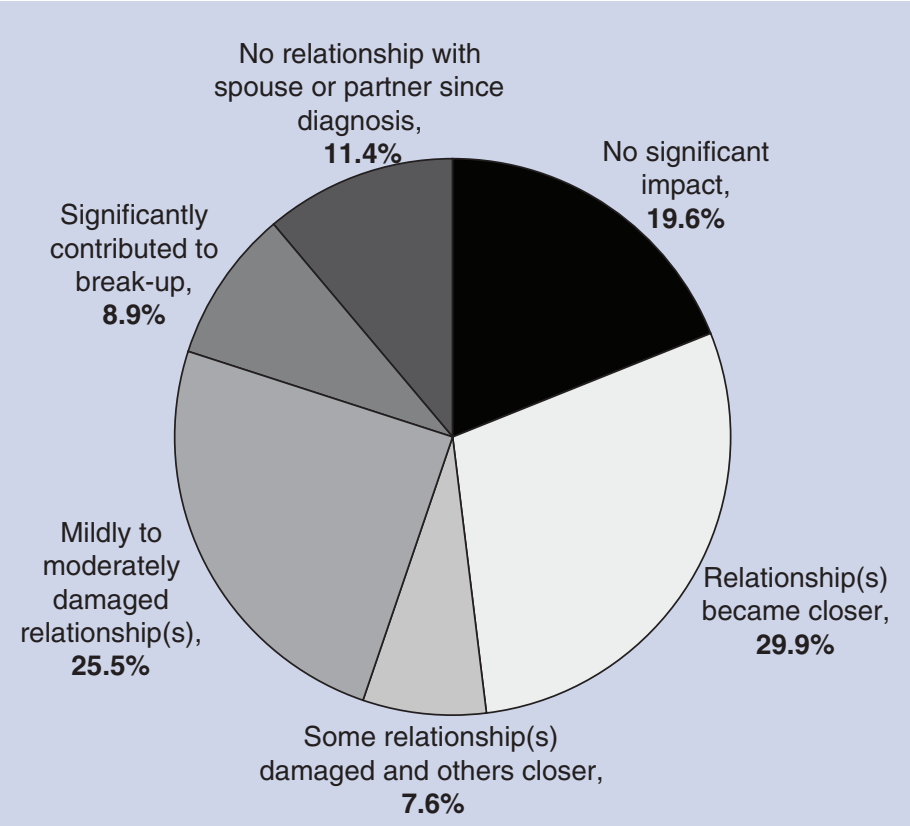

Figure 1. Impact of having multiple sclerosis on relationships with current or previous spouse(s) and/or partner(s) $(n=1010)$.

Forty percent of participants reported that their spouse or partner understood the impact of MS on the participant; however, these participants also felt that they burdened their spouse or partner with their problems. The remaining participants felt that their spouse or partner understood the impact of MS and participants were glad about this $(39.8 \%)$; that their spouse or partner did not understand the impact of MS and this made participants sad/upset (15.2\%); or that their spouse or partner did not understand the impact of MS but that it was okay (5.0\%).

A minority of participants had strongly negative perceptions of their relationship with their spouse or partner (Figure 2). Nearly 25\% of participants reported that their spouse or partner questions if their MS symptoms are real or as severe as they are. Similarly, only a minority believed that their spouse or partner felt they exaggerated their symptoms $(18.8 \%)$ or accused them of being lazy or selfish (16.9\%). Participants were more likely to disagree $(53.2 \%)$ than agree $(22.4 \%)$ with the statement that their spouse or partner resented the patient's inability to do things with them.

The RAS was completed by 777 participants, with an overall mean score of 3.9 and a median score of 4.1 . Using the preassigned RAS categories, significantly more participants ( $\mathrm{n}=452,58.2 \%$ ) were satisfied with their current relationship (defined as RAS $\geq 4$ ), than those who were not satisfied (RAS $<4 ; \mathrm{n}=325,41.8 \%$; $<<0.0002$ ). A significantly higher proportion of men than women were satisfied with their relationship (71.3 vs 56.2\%; $\mathrm{p}=0.0042$ ). Comparing participants who are and are not currently being treated with an MS disease-modifying medication, no difference was seen in the proportion of respondents who reported satisfaction with their relationships $(59.4 \%$ of those being treated and $54.3 \%$ of those not being treated).

Regardless of disability or pain severity level, participants were typically satisfied in their relationships. Across all levels of the PDDS levels of disability, as well as the four pain severity categories, more than half of respondents reported relationship satisfaction (Table 3). One exception was a slight dip in the proportion of respondent with moderate disability who reported relationship satisfaction (48.6\%), though this was not statistically significant. We also observed a slight decline in relationship satisfaction with the increase in pain levels.

The average scores on the walking ability, fatigue impact, and pain severity level and pain impact scales were calculated and compared between two RAS categories (Table 4). The average fatigue impact score was significantly lower for satisfied versus not satisfied respondents $(\mathrm{p}<0.03)$, and the average pain impact score was significantly lower $(\mathrm{p}<0.0004$ ) for satisfied versus not satisfied respondents. The average walking ability and pain severity scores did not significantly differ between the satisfied and not satisfied respondents. 


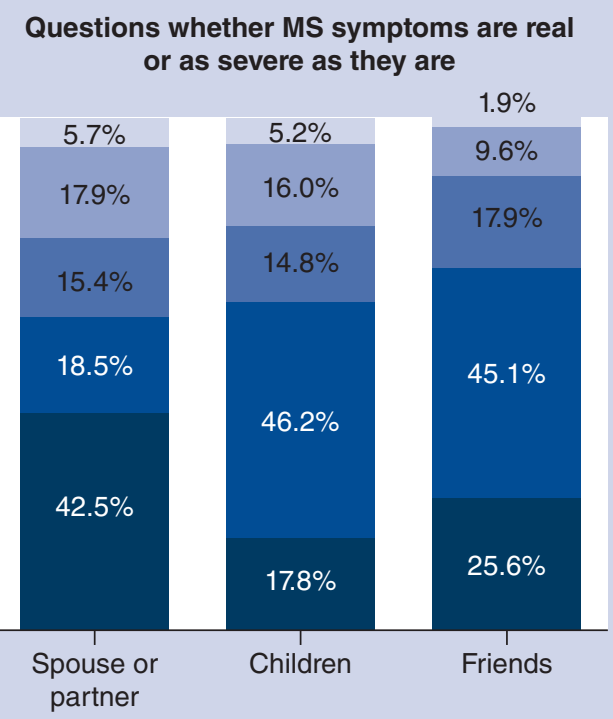

Thinks I exaggerate my symptoms

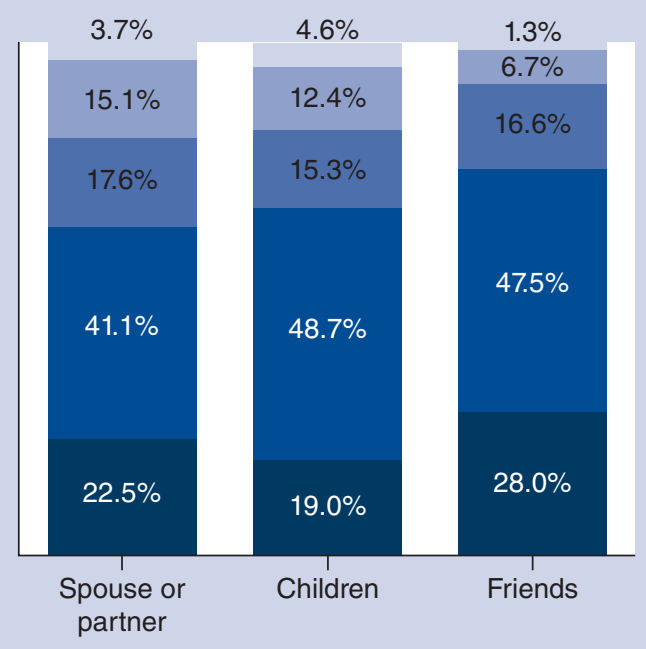

Resents when I am unable to do things with them

Has accused me of being lazy or selfish

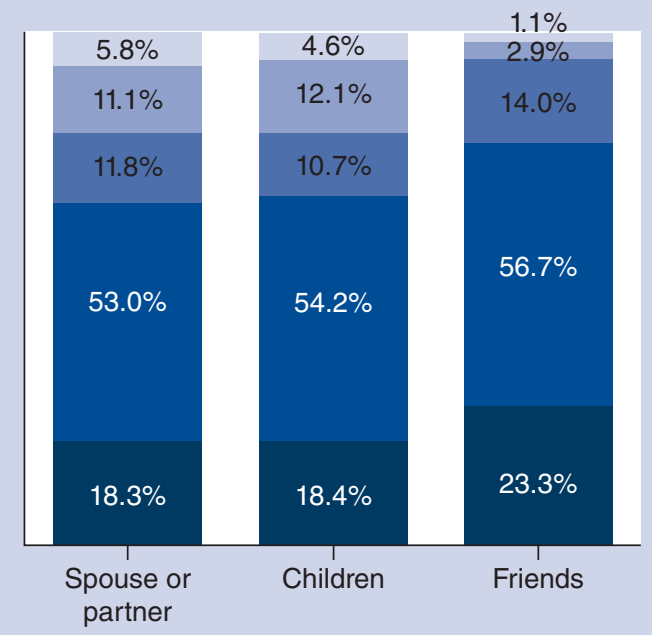

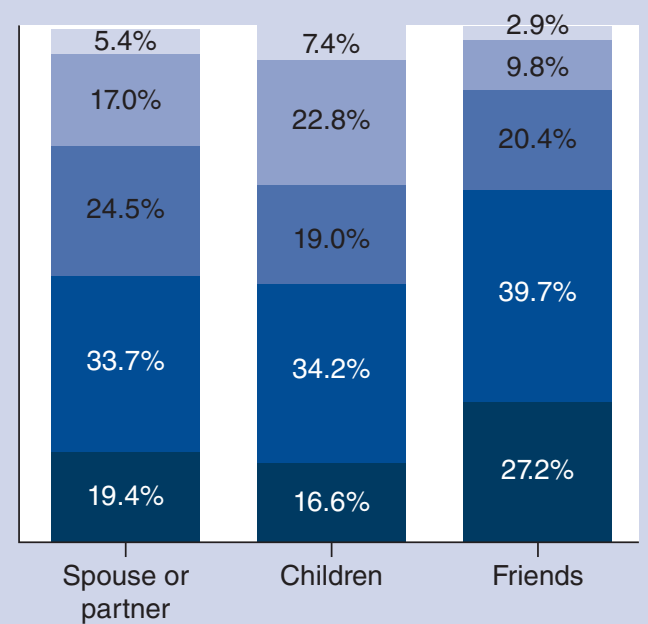

\begin{tabular}{|ll|}
\hline Strongly agree & Disagree \\
Agree & Strongly disagree \\
Neither disagree nor agree & \\
\hline
\end{tabular}

Figure 2. Relationship perceptions across connection type.

MS: Multiple sclerosis.

\section{Relationships with children}

A total of 695 participants reported that they had at least one child who was old enough to understand MS. A total of 675 participants' children knew they had MS; these respondents completed questions about the impact of MS on the relationship with their children. A minority of participants had strongly negative perceptions of their relationship with their children (Figure 2). A minority of participants reported that their children question if their MS symptoms are real or as severe as they are (21.2\%). Similarly, only a minority believed that their children felt they exaggerated their symptoms $(17.0 \%)$ or accused them of being lazy or selfish (16.7\%). Participants were more 


\begin{tabular}{|c|c|c|}
\hline Level of disability (PDDS) & Satisfied (RAS $\geq 4) n(\%)$ & Not satisfied (RAS <4) n (\%) \\
\hline Normal $(n=148)$ & $70(61.4)$ & $44(38.6)$ \\
\hline Mild disability $(n=98)$ & $45(55.6)$ & $36(44.4)$ \\
\hline Moderate disability $(n=142)$ & $52(48.6)$ & $55(51.4)$ \\
\hline Gait disability $(n=182)$ & $78(55.7)$ & $62(44.3)$ \\
\hline Early cane $(n=186)$ & $91(60.7)$ & $59(39.3)$ \\
\hline Late cane $(n=140)$ & $65(61.9)$ & $40(38.1)$ \\
\hline Bilateral support $(n=55)$ & $26(65.0)$ & $14(35.0)$ \\
\hline Wheelchair/scooter $(n=52)$ & $22(61.1)$ & $14(38.9)$ \\
\hline Bedridden $(n=7)$ & $3(75.0)$ & $1(25.0)$ \\
\hline \multicolumn{3}{|l|}{ Pain severity category } \\
\hline No pain $(n=110)$ & $52(69.3)$ & $23(30.7)$ \\
\hline Mild pain $(n=283)$ & $128(58.4)$ & $91(41.6)$ \\
\hline Moderate pain $(n=317)$ & $144(56.9)$ & $109(43.1)$ \\
\hline Severe pain $(n=300)$ & $128(55.7)$ & $102(44.3)$ \\
\hline
\end{tabular}

\begin{tabular}{|c|c|c|}
\hline & \multicolumn{2}{|c|}{ Relationship satisfaction category } \\
\hline & Satisfied (RAS $\geq 4 ; n=452$ ) & Not satisfied (RAS $<4 ; n=325$ ) \\
\hline Average walking ability score (MSWS-12) & 36.5 & 36.6 \\
\hline Average fatigue impact score (MFIS-5)* & 12.7 & 13.4 \\
\hline Average pain severity score (NRS) & 4.3 & 4.7 \\
\hline Average pain impact score $(\mathrm{PES})^{* *}$ & 16.9 & 18.6 \\
\hline
\end{tabular}

likely to disagree $(50.8 \%)$ than agree $(30.2 \%)$ with the statement that their children resented the patient's inability to do things with them.

\section{Relationships with close friends}

A total of 806 participants reported that they had close friends. A total of 794 participants' close friends knew they had MS; these participants completed questions about the impact of MS on the relationship with their close friends. A minority of participants had strongly negative perceptions of their relationship with their close friends (Figure 2). A minority of participants reported that their friends question if their MS symptoms are real or as severe as they are (11.5\%). Similarly, only a minority believed that their friends felt they exaggerated their symptoms $(7.9 \%)$ or accused them of being lazy or selfish (4.0\%). Participants were more likely to disagree $(66.9 \%)$ than agree $(12.7 \%)$ with the statement that their friends resented the patient's inability to do things with them.

\section{Relationship advice}

A total of 1010 participants completed questions pertaining to relationship advice to others with MS. A majority of participants felt that another person with MS should tell someone that he/she recently started dating about having MS within the first several dates (32.6\% thought first date and 31.1\% thought after several dates). A majority $(64.3 \%)$ of participants thought that it is somewhat likely that disclosing an MS diagnosis will damage a new romantic relationship, whereas a majority $(59.7 \%)$ of participants thought that it is not very likely to damage a new friendship. Interestingly, some participants avoid starting new relationships (18.9\%) or friendships (19.8\%) because of their MS. 
Table 5. Common themes expressed by participants in the free response question.

\begin{tabular}{|c|c|}
\hline Theme & Example comments \\
\hline Fatigue and being too tired to engage with others & $\begin{array}{l}\text { "Very few friends because I am too tired to be a good friend, to give back when needed, people are put off } \\
\text { because they do not understand the invisible reason I do not join in - fatigue - and how it affects everything" } \\
\text { "Tiring easily and resting at intervals decreases my time with friends" } \\
\text { "At times, my family does not realize the extent of fatigue. I work full time as a recovery room RN which } \\
\text { means I am on my feet most of the day. I still push to do activities when I get home, but I am tired!" }\end{array}$ \\
\hline Lack of understanding by some & $\begin{array}{l}\text { "People do not seem to understand what you are going through" } \\
\text { "Family does not understand; husband does because he sees me every day" } \\
\text { "You look fine so it is hard for someone to understand!!!" } \\
\text { "When some people who you thought were your friends for years find out you have MS they change how they } \\
\text { act toward you or avoid you because they do not understand what MS is and are not willing to learn about it } \\
\text { and realize it is not contagious." } \\
\text { "Very hard to get understanding when symptoms change, wax and wane" }\end{array}$ \\
\hline Unable to 'normal' activities & $\begin{array}{l}\text { "Being unable to do more physical things than before" } \\
\text { "It is hard to express the inability to do the things you used to do with ease. Having been mobile for most of } \\
\text { my life and now having to think of every movement you make whether it is going to affect you or people } \\
\text { around you when movement is made. Having developed MS later in life. I never thought in my wildest dreams } \\
\text { that I would get such an impact on my life. But life goes on and I have to make the best of it" } \\
\text { "Because many of my friends hiked and traveled with me before MS symptoms affected my ability to walk, MS } \\
\text { has isolated me from many of my friends and the activities I loved" }\end{array}$ \\
\hline Avoidance of others & $\begin{array}{l}\text { "Prefer to be alone. Tend to stay away from people" } \\
\text { "Afraid to start friendship because of MS" } \\
\text { "I avoid large groups, avoid activities in large groups" }\end{array}$ \\
\hline Feel like a burden on others & $\begin{array}{l}\text { "I just feel like I am a burden because I cannot help with much of anything" } \\
\text { "Just the fear of becoming a burden to family and friends is a fear since I have always been very independent" } \\
\text { "My husband is very supportive; however, I always feel like I'm a burden. Sometimes in his concern for me. he } \\
\text { hovers over me and I have to tell him to let me try" }\end{array}$ \\
\hline Having a good support system is beneficial & $\begin{array}{l}\text { "Friends are very supportive of my MS. They have been there since my divorce } 13 \text { years ago. They were already } \\
\text { aware of my MS. Continue to get strength from them" } \\
\text { "Friends understand and are more willing to give you a break then significant others are" } \\
\text { "I am fortunate at my age that friendships and relationships are well established" }\end{array}$ \\
\hline Impact on sex life & $\begin{array}{l}\text { "Less intimacy with your spouse leads to resentment on the part of the spouse that you cannot perform like } \\
\text { you used to when you were a healthy } 20 \text {-something" } \\
\text { "MS has affected the sexual relationship I have with my spouse" } \\
\text { "Sex is nonexistent and has been for } 5 \text { years" }\end{array}$ \\
\hline
\end{tabular}

Free responses

A total of 471 participants completed the free-response question, and several themes emerged. The impacts of fatigue and of a perceived lack of understanding by others were commonly mentioned as barriers to participants' engaging in relationships with others. Participants also commented that they are unable to do the normal things that they once did, which has an impact on both their relationships with others and their own self-esteem. Participants reported feelings of isolation and deliberate avoidance of others because of their MS. Whereas a minority of comments described supportive relationships, particularly more so from friends, most free-response comments focused on the negative effects on family and social relationships (Table 5). These responses suggest that MS has a more detrimental effect on less intimate relationships than on close friends and family. It is possible to infer that the secondary effects of fatigue and pain, such as social isolation and the inability to participate in typical activities, limit acquaintances for people with MS.

\section{Patients with MS \& fibromyalgia sufferers}

Analysis was conducted between this sample of 1010 adults diagnosed with MS and a sample of 6126 adults diagnosed with fibromyalgia that were included in a previous study [7] to examine similarities and differences between these two populations. Fibromyalgia, like MS, is a chronic disabling condition characterized by many similar symptoms such as fatigue, pain and depression.

There were 777 participants in a relationship in the MS sample and 4647 in the fibromyalgia sample [7]. A total of 4576 participants in the fibromyalgia sample completed the RAS. The mean RAS score for participants with MS (3.9) was significantly higher than that for participants with fibromyalgia $(3.7 ; \mathrm{p}<0.0001)$. Using the preassigned RAS categories, 452 (58.2\%) individuals in the MS sample were satisfied with their current relationship (defined as RAS $\geq 4$ ) compared with 325 (41.8\%) who were not satisfied (RAS <4). In the fibromyalgia sample, 2265 participants $(49.5 \%)$ were satisfied with their current relationship and 2311 (50.5\%) participants were not 
Table 6. Participants' description of spouse's or partner's understanding of their medical condition (fibromyalgia,

$\mathrm{n}=4617$; multiple sclerosis, $\mathrm{n}=777$ ).

\begin{tabular}{|c|c|c|}
\hline Level of understanding & Fibromyalgia, n (\%) & MS, n (\%) \\
\hline My spouse/partner does not understand the impact of my condition and that is ok & $275(6.0)$ & $39(5.0)$ \\
\hline My spouse/partner does not understand the impact of my condition and that makes me sad/upset* & $1019(22.1)$ & $118(15.2)$ \\
\hline My spouse/partner understands the impact of my condition and I am glad he/she understands* & $1242(26.9)$ & $309(39.8)$ \\
\hline My spouse/partner understands the impact of my condition but I feel that I burden him/her with my problems** & $2081(45.1)$ & $311(40.0$ \\
\hline${ }^{\star} p<0.0001 ;{ }^{* *} p=0.0044$ & & \\
\hline
\end{tabular}

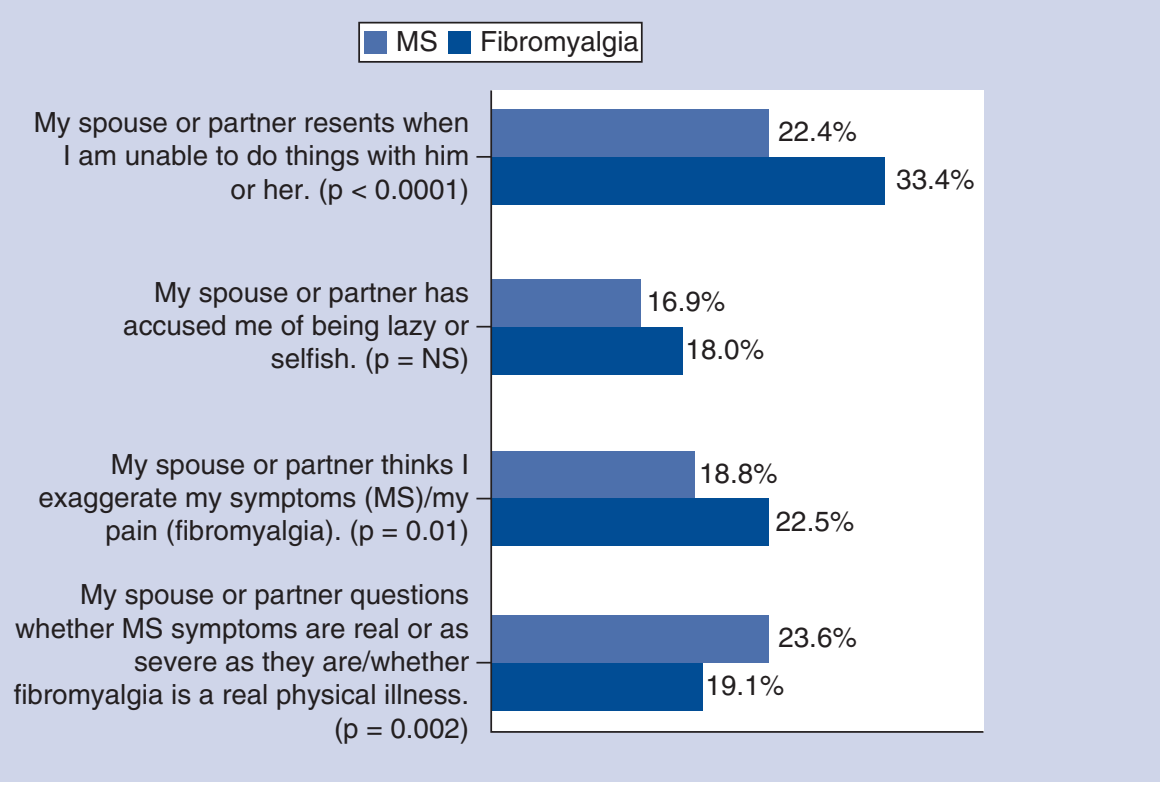

Figure 3. Percent agreement with partner or spouse relationship perceptions by medical condition.

MS: Multiple sclerosis.

satisfied. A significantly greater proportion of patients with MS were satisfied with their relationships compared with patients with fibromyalgia $(\mathrm{p}<0.0001)$.

Significant differences were seen between MS and fibromyalgia on the level of understanding of participants' medical condition by their spouse or partner for three of the four levels (Table 6). Participants with MS perceived their spouse or partner to have a deeper and more positive level of understanding than participants with fibromyalgia.

Whereas a minority of participants from both samples had strongly negative perceptions of their relationship with their spouse or partner, participants with fibromyalgia were significantly more likely to have negative perceptions than participants with MS in the areas of resentment and symptom/pain exaggeration (Figure 3). When asked to rate their perception of whether their spouse or partner questions the severity of their MS or whether fibromyalgia is thought to be a real physical illness, MS participants were significantly more likely to have negative perceptions compared with participants with fibromyalgia.

A total of 675 participants with MS and 4341 participants with fibromyalgia completed questions about the impact of their condition on the relationship with their children. Similar to the spouse and partner relationship perceptions, participants with fibromyalgia were more likely to have negative perceptions than those with MS (Figure 4). Significantly more participants with fibromyalgia than MS agreed with the statements that their child/children resent when the participant is unable to do things with them or think that the participant exaggerates symptoms/pain.

A total of 794 participants with MS and 4361 participants with fibromyalgia completed questions about the impact of their condition on the relationship with close friends. On all four perception ratings, participants with 


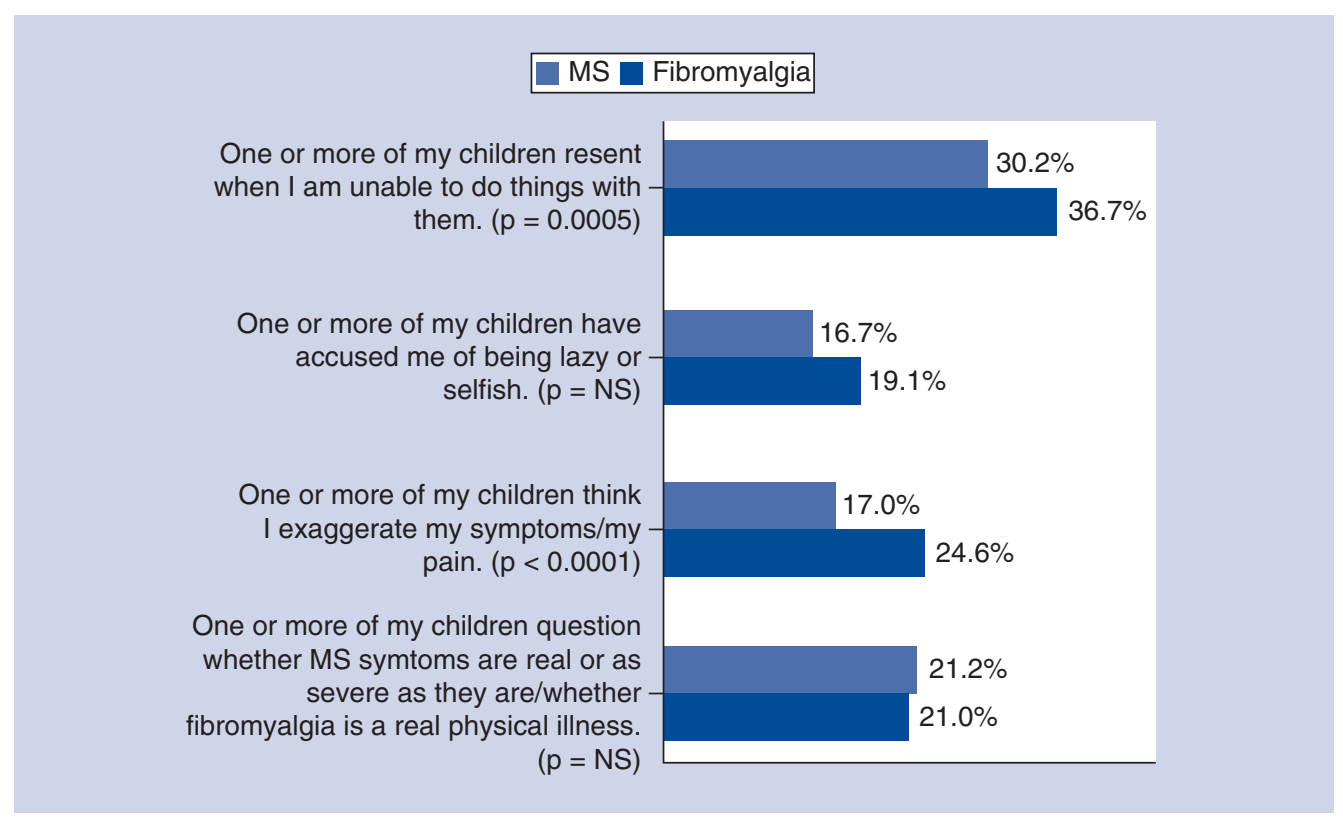

Figure 4. Percent agreement with children relationship perceptions by medical condition. MS: Multiple sclerosis; NS: Nonsignificant.

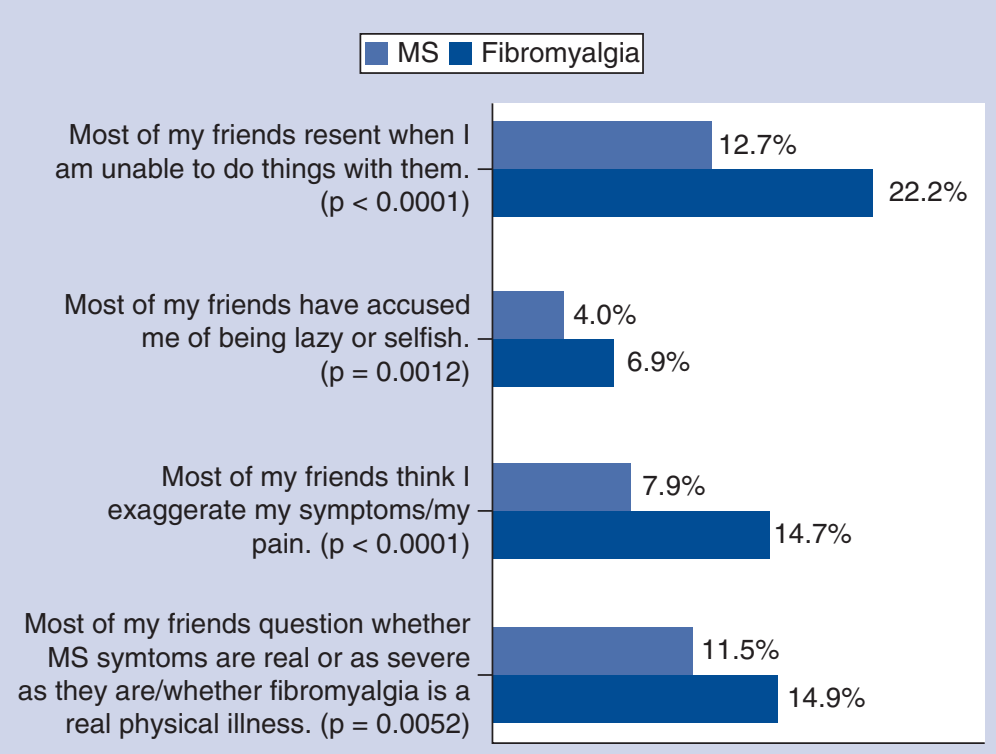

Figure 5. Percent agreement with friend relationship perceptions by medical condition. MS: Multiple sclerosis; NS: Nonsignificant..

fibromyalgia were significantly more likely to have negative perception ratings of their relationships with their friends than participants with MS (Figure 5).

\section{Discussion}

Individuals with MS at all levels of disability and degrees of symptom impact were represented in this convenience sample. Participants were equally likely to report feeling that their health problems burdened their partner and were glad that their partner is understanding. 
Few participants had strongly negative perceptions of their relationship with their romantic partner. Participants reported satisfaction with their current relationship more often than not, regardless of pain severity and at almost every level of disability. Less than a quarter of participants felt that their partner resented their inability to participate in activities. Nearly $80 \%$ of respondents agreed with statements indicating that their partner understands the impact of MS.

Despite this high level of understanding from their partners, many participants indicated by their multiple choice answers and free responses that they feel like a burden. Such feelings may explain the dip in relationship satisfaction among patients with moderate disability. A total of $48.6 \%$ of people with a PDSS indicating moderate disability reported that they were satisfied with their relationships compared with $61.4 \%$ of people with no relative disability.

As individuals with MS transition from mild to moderate disability, they likely become more dependent on their partners, and couples may face challenges navigating changing family roles. Indeed, previous studies of couples have demonstrated the profound effect of MS on couples as they adjust to the illness over time [5,6]. One study of 160 couples evaluated distress and positive adjustment in both partners [5]. The results showed decreases in positive effect and perception of relationship quality over a 12-month period. Findings from another study showed that as disease severity increased, patients were less likely to continue gainful employment, maintain social contacts and continue leisure activities [6]. In $57 \%$ of cases, the professional careers of the patient's relatives were also affected, and the standards of living declined for $37 \%$ of patients and their families since the MS diagnosis. Nevertheless, no increase in divorce or separation was observed in this study population. Indeed, one comparative study showed no difference in relationship variables (e.g., relationship satisfaction, feeling intimate, respected or understood; total relationship quality) between couples with and without MS [4]. It is heartening that, in our survey, the majority of respondents with the greatest disability and most severe pain report being satisfied in their relationship. In the present study, the factors that were significantly associated with relationship satisfaction were lower pain impact scores and lower fatigue scores.

Not all previous studies have reported such sanguine relationship outcomes [18]. In the present survey, nearly twothirds (61.1\%) of respondents who cited that MS contributed to the end of a romantic relationship indicated that the healthy partner feared that having a partner with MS would become a burden. Additionally, our results indicate that as many as one-fifth of patients with MS are in relationships with partners who question their symptoms, believe they exaggerate their symptoms, or accuse them of being lazy or selfish. Almost two-thirds of participants believe that it is important to disclose an MS diagnosis very early in a romantic relationship even though many believe this information is somewhat likely to damage the relationship.

One hypothesis-generating finding of this study is that women were significantly less likely than men to report relationship satisfaction. The literature on the effects of gender on relationship satisfaction in the context of MS is sparse [5]. Information from a small qualitative study with the spouses of a person with MS suggests that role reversals and need for emotional support may contribute to gender differences in relationship satisfaction [19]. The caregiving husband and wives in this study believed 'the caregiver role was congruent for women and not for men'. Men and women approached caregiving differently: men took on the role of protector, whereas women advocated for their husbands and encouraged them to remain independent and involved. The men in this study provided tangible support to their wives with MS, taking responsibility for household chores, giving injections and accompanying their wives to appointments. The men responded with anger to the lack of understanding from friends and family, and at the environmental barriers their wives had to overcome. It would be interesting, in a future study, to examine how women with MS perceive this well-intended form of support, and to what extent this approach to caregiving fulfills their need for emotional support.

Relationship counseling might help couples to develop realistic expectations and healthy coping strategies. Participation in a relationship enrichment program developed by the National Multiple Sclerosis Society, called Relationship Matters, has been shown to increase relationship satisfaction and health-related quality of life 3 months after program completion [20]. At follow-up, $80 \%$ of program participants reported reduced relationship conflict and $81 \%$ said their ability to discuss MS challenges with their partner had improved. Qualitative research has highlighted factors that help and hinder coping as a couple and suggests that 'couple identity' can alleviate some of the stress of caregiving [21]. A growing body of literature emphasizes the need to develop and offer supportive services to the couple jointly [21]; however, access to relationship and family counseling remains suboptimal [22].

Parental illness can be a major source of stress and uncertainty for children, and unfortunately, research in this area is limited [23]. In the present study, 30.2\% of respondents reported resentment from their children. As a parent's ability to perform certain tasks declines, family roles necessarily shift. Indeed, findings from one 
qualitative study echo our results, with many children expressing resentment associated with the need to take on extra responsibility [24]. In other studies, children of parents with MS felt a greater sense of burden, anger and low life satisfaction compared with children with healthy parents because of their obligations [23]. However, disability theorists and researchers have pointed out that being a child of a chronically ill parent means growing up on a continuum that is at times oppressing and at other times empowering [25]. In the qualitative study referenced earlier, some children expressed pride in their family responsibilities [24], and it is remarkable that in the present survey, nearly $70 \%$ of respondents do not feel resentment from their children.

Studies of social support often categorize family/friends together, obscuring differences among these relationships. It is a strength of the present study that individuals with MS were asked to assess the impact of their disease on these types of relationship separately. Study participants generally perceived relationships with their close friends to be better than relationships with their romantic partners or children. Only $12.7 \%$ of respondents felt resentment from their friends about their inability to participate in activities, and more than half (59.7\%) thought disclosing an MS diagnosis was unlikely to damage a new friendship. However, the free responses alluded to the isolation that some people feel when they cannot participate in activities with friends, and one in five respondents has avoided starting a new friendship because of MS. The free responses are consistent with qualitative studies of severely affected individuals, who report that friendship networks typically decrease as disease severity increases, but the desire for contact and understanding does not $[6,26]$. Future research could be conducted to evaluate how disease severity affects the quality and quantity of friendships. It could be interesting to understand what individuals with MS expect of friends compared with partners, and how those expectations impact their perception of the relationships.

\section{MS versus fibromyalgia}

Comparing this study's sample to that of a previous study in adults diagnosed with fibromyalgia, the mean RAS score for participants with MS (3.9) was significantly higher than the mean RAS score for participants with fibromyalgia (3.7) [7]. Using the preassigned RAS categories, a significantly higher proportion of individuals were satisfied with their relationships within the MS sample than within the fibromyalgia sample. Significant differences were found between the two conditions on their spouse's or partner's level of understanding, for three of the four levels, illustrating that participants with MS perceived their spouse or partner to have a deeper and more positive level of understanding compared with participants with fibromyalgia. However, it should be noted that patients could not be matched in terms of demographic information and disease severity, which may affect findings.

Whereas a minority of participants from both samples had strongly negative perceptions of their relationship with their spouse or partner, participants with fibromyalgia were more likely to have negative perceptions than participants with MS. This trend continued for participants with fibromyalgia because they were more likely to have negative perceptions than those with MS in their relationships with their children, as well as relationships with close friends.

\section{Study limitations}

The study's sample size had an adequate level of statistical power; however, interpretation of these data was limited by design issues inherent with using convenience sampling. Individuals were recruited from MultipleSclerosis.net and the MultipleSclerosis.net Facebook page. Patients who opted to participate might not have been representative of typical community or MS patient samples. First, more women completed the survey than men and, although MS affects more women than men, this should be noted as a limitation. Second, patients may have been more likely to come from the less severe spectrum of the EDSS scale. Finally, patients recruited through these methods may have had increased knowledge about the progression, treatment and coping strategies of the disease, which may have influenced study results. More research needs to be done to determine whether study findings are consistent across patient populations recruited in other ways.

Convenience sampling in relapsing-remitting MS is particularly challenging because an individual's perception of the impact that MS has on his or her life may vary greatly depending on whether he or she is relapsing or in remission. In addition, relationship questions were not asked of non-MS patients to determine if the fatigue or pain levels reported by participants with MS are unique to this condition or might be seen in healthy individuals or those with other chronic illnesses.

Furthermore, because a majority of participants indicated that their MS began after their relationship started, research should study the effects longitudinally by including a wider representation of individuals whose MS began before a relationship started. A review of studies evaluating marital relationships among patients with chronic pain 
found that pain severity was generally not linked with marital satisfaction, anxiety and depression were linked with marital satisfaction, and treatment improved both psychological distress and marital satisfaction [27].

Further research should also include investigations exploring sexual/intimacy issues, which were frequently mentioned in the free-response option and commonly reported as an issue in patients with MS. Also, patients with MS should be queried to determine if they have discussed important relationship problems with their healthcare providers. Finally, as these were patient self-reported data, further studies should collect relationship data from both patient and their loved ones.

\section{Conclusion}

The majority of individuals with MS have positive relationships with their romantic partners, children and close friends. More than half of individuals at all levels of disability and pain severity report being satisfied with their relationship with romantic partners, with the exception of a small dip among patients with moderate disability. Compared with patients with fibromyalgia, patients with MS were more likely to report relationship satisfaction and a more positive level of understanding from their partner.

Nevertheless, the free responses reveal the challenges faced by patients with MS in maintaining romantic and social relationships. Future research should focus on identifying the effective coping strategies used by satisfied couples and improving access to high-quality relationship-enrichment programs for couples with MS.

\section{Future perspective}

The authors of this manuscript would argue that there has been a greater focus on a more holistic approach to patient care, especially as many conditions are now considered chronic instead of life-threatening. This increased focus includes placing more emphasis on patient beliefs and perspectives, patient relationship dynamics and treatment options beyond traditional medicine. With regard to understanding patient relationship dynamics, patients should seek out relationship-enrichment programs, which may be in the form of self-educational units for patients, support groups or online forums. Physicians will need to be able to provide guidance and recommendations to the patient regarding access to high-quality relationship-enrichment programs. Our study begins to explore that need, and future research will help shape the recommendations physicians provide to patients regarding positive relationship-building between loved ones.

\section{Acknowledgments}

The authors thank Rock Heyman, MD, Director of the Multiple Sclerosis Care Center at the Magee-Womens Hospital, University of Pittsburgh Medical Center, for assistance with this study. The authors also acknowledge the deceased, Dawn Marcus, MD, for her invaluable contributions to this research study.

\section{Author contributions}

LB Herbert contributed with data analysis and interpretation. K Zerkowski contributed with survey development, data collection and interpretation, and drafting the manuscript. S O'Brien contributed with data interpretation and drafting the manuscript. KV Leonard contributed with data interpretation, drafting the manuscript, and coordinating manuscript development. A Bhowmick contributed with survey development, data collection and interpretation, and drafting the manuscript.

\section{Financial \& competing interests disclosure}

The manuscript was financially supported by Health Union LLC (PA, USA), a company that employs the authors of this manuscript. Note that Sarah O'Brien is employed by Health Union as a contractor. Health Union LLC receives funding from pharmaceutical companies that may be developing or currently marketing MS drugs, and this manuscript discusses MS as a topic. The authors have no other relevant affiliations or financial involvement with any organization or entity with a financial interest in or financial conflict with the subject matter or materials discussed in the manuscript apart from those disclosed.

Editorial assistance was provided by E4 Health Group (PA, USA), formerly Connexion Healthcare (PA, USA), in the form of editing the manuscript, aiding in preparation of the figures and aiding in the preparation for submission. Funding was provided by Health Union LLC (PA, USA).

\section{Open access}

This work is licensed under the Attribution-NonCommercial-NoDerivatives 4.0 Unported License. To view a copy of this license, visit http://creativecommons.org/licenses/by-nc-nd/4.0/ 


\section{References}

Papers of special note have been highlighted as: $\bullet$ of interest; $\bullet \bullet$ of considerable interest

1. Dutta R, Trapp BD. Relapsing and progressive forms of multiple sclerosis: insights from pathology. Curr. Opin. Neurol. 27(3), 271-278 (2014).

2. Feinstein A, Freeman J, Lo AC. Treatment of progressive multiple sclerosis: what works, what does not, and what is needed. Lancet Neurol. 14, 194-207 (2015).

3. Gelfand JM. Multiple sclerosis: diagnosis differential diagnosis, and clinical presentation. Handb. Clin. Neurol. 122, 269-290 (2014).

4. McCabe MP, McDonald E. Perceptions of relationship and sexual satisfaction among people with multiple sclerosis and their partners. Sex. Disabil. 25(4), 179-188 (2007).

5. Samios C, Pakenham KI, O'Brien J. A dyadic and longitudinal investigation of adjustment in couples coping with multiple sclerosis. Ann. Behav. Med. 49(1), 74-83 (2015).

-• Mixed-model analysis of variance found that patients reported poorer adjustment than their spouse on a range of adjustment indicators and that positive affect and relationship satisfaction declined overtime for both patients and spouses. Intraclass correlations found that patient and spouse scores on all adjustment indicators were related at Time 1. Multilevel modeling showed that one's partner's relationship satisfaction at Time 1 positively predicted one's own relationship satisfaction at Time 2 .

6. Hakim EA, Bakheit AM, Bryant TN et al. The social impact of multiple sclerosis: a study of 305 patients and their relatives. Disabil. Rehabil. 22(6), 288-293 (2000).

-• Multiple sclerosis (MS) has a profound impact on patients' social roles and their relatives' well-being. In contrast to previous studies, a high divorce/separation rate among patients with MS was not observed. Severe disability and cognitive impairment are predictors of loss of employment, decline in standard of living, and withdrawal from social and leisure activities among patients and are strong indicators of stress among relatives.

7. Marcus DA, Richards KL, Chambers JF, Bhowmick A. Fibromyalgia family and relationship impact exploratory survey. Musculoskeletal Care 11(3), 125-134 (2013).

8. Wallin MT, Culpepper WJ, Campbell JD et al. US Multiple Sclerosis Prevalence Workgroup. The prevalence of MS in the United States: a population-based estimate using health claims data. Neurology 92(10), e1029-e1040 (2019).

9. National Multiple Sclerosis Society. MS Prevalence (2018). www.nationalmssociety.org/About-the-Society/MS-Prevalence

10. Hohol MJ, Orav EJ, Weiner HL. Disease steps in multiple sclerosis: a simple approach to evaluate disease progression. Neurology 45(2), 251-255 (1995).

11. Hohol MJ, Orav EJ, Weiner HL. Disease steps in multiple sclerosis: a longitudinal study comparing disease steps and EDSS to evaluate disease progression. Mult. Scler. 5(5), 349-354 (1999).

12. Hobart JC, Riazi A, Lamping DL, Fitzpatrick R, Thompson AJ. Measuring the impact of MS on walking ability: the 12-item MS Walking Scale (MSWS-12). Neurology 60(1), 31-36 (2003).

13. The Consortium of Multiple Sclerosis Centers Health Services Research Subcommittee MSQLI multiple sclerosis quality of life inventory: a user's manual. National Multiple Sclerosis Society (1997). www.nationalmssociety.org/NationalMSSociety/media/MSNationalFiles/Brochures/MSQLI_-A-User-s-Manual.pdf

14. Hendrick SS. A generic measure of relationship satisfaction. J. Marriage Family 50(1), 93-98 (1988).

15. Hendrick SS, Dicke A, Hendrick C. The Relationship assessment scale. J. Social Personal Relationships 15, 137-142 (1998).

16. Vaughn MJ, Baier MM. Reliability and validity of the relationship assessment scale. Am. J. Family Ther. 27(2), 137-147 (1999).

17. Wachholtz A, Bhowmick A, Herbert LB, Marcus D. More is not always better: an epidemiological assessment of migraine frequency and the impact on relationships. J. Pain Manag. Med. 3(2), 126 (2017).

18. Gold-Spink E, Goldman Sher T, Theodos V. Uncertainty in illness and optimism in couples with multiple sclerosis. Int. J. Rehabil. Health 5(3), 157-164 (2000).

- Relationships among uncertainty in illness, optimism, symptom severity and depression in 18 individuals with multiple sclerosis and their partners were examined. Levels of depression in patients positively related to levels of uncertainty in their partners. Results also suggest negative correlations between patients' levels of optimism and levels of uncertainty in both partners.

19. Courts NF, Newton AN, McNeal LJ. Husbands and wives living with multiple sclerosis. J. Neurosci. Nurs. 37(1), 20-27 (2005).

20. Tompkins SA, Roeder JA, Thomas JJ, Koch KK. Effectiveness of a relationship enrichment program for couples living with multiple sclerosis. Int. J. MS Care 15(1), 27-34 (2013).

21. Boland P, Levack WM, Hudson S, Bell EM. Coping with multiple sclerosis as a couple: 'peaks and troughs' - an interpretative phenomenological exploration. Disabil. Rehabil. 34(16), 1367-1375 (2012).

- The first theme illustrates the factors that hampered effective coping in relation to how couples cope with one another on a day-to-day basis. The second theme relates to how couples view themselves in the future. It became evident that these two themes are underpinned by the ability of participants to find strength in their own sense of self (faith in self), as well as the importance of having their spouses present through the ups and downs of the illness (faith in each other). 
22. McCabe MP, Ebacioni KJ, Simmons R, McDonald E, Melton L. Unmet education psychological and peer support needs of people with multiple sclerosis. J. Psychosom. Res. 78(1), 82-87 (2015).

- In terms of psychological services, females were less satisfied with their access to relationship and family counseling. A clear need also exists for more variety both in peer support groups and in times and modes of communication, especially among young people and mildly affected groups. Symptom severity was associated with a greater need for almost all education and psychological support services.

23. Razaz N, Nourian R, Marrie RA, Boyce WT, Tremlett H. Children and adolescent's adjustment to parental multiple sclerosis: a systematic review. BMC Neurol. 14, 107 (2014).

24. Turpin M, Leech C, Hackenberg L. Living with parental multiple sclerosis: children's experiences and clinical implications. Can. J. Occup. Ther. 75(3), 149-156 (2008).

- Parental multiple sclerosis (MS) affects the roles and responsibilities of all family members. Additional responsibilities can enhance children's skills and provide both pride and stress. Children may require additional support because they are reluctant to discuss their parent's MS with peers and may lack adult support apart from parents (with or without MS). Social and practical support for the parent could reduce children's anxiety levels.

25. Blackford KA. A child's growing up with a parent who has multiple sclerosis: theories and experiences. Disabil. Soc. 14, 673-685 (1999).

26. Galushko M, Golla H, Strupp J et al. Unmet needs of patients feeling severely affected by multiple sclerosis in Germany: a qualitative study. J. Palliat. Med. 17(3), 274-281 (2014).

27. Leonard MT, Cano A, Johansen AB. Chronic pain in a couples context: a review and integration of theoretical models and empirical evidence. J. Pain 7(6), 377-390 (2006). 
